\title{
TITLE: NON-INVASIVE MEASUREMENTS OF CARDIAC OUTPUT AFTER CARDIAC SURGERY
}

AUTHORS: Ludwik Fedorko PhD, MD, David Preiss BSc, Joseph Fisher MD, George Djaiani MD, Jo Carroll RN, L. Minkovich MD, Azami Takafumi MD, George Volgyesi P. Eng.

AFFILIATION: Department of Anesthesia \& Pain Management, Toronto General Hospital, University Health Network, University of Toronto, 200 Elizabeth Street, Toronto, ON, Canada M5G 2C4

INTRODUCTION: Cardiac output (Q) and mixed venous oxygen saturation (SvO2) are important clinical indicators of heart failure. These are difficult to obtain after discharge from the intensive care unit (CVICU). Measuring (Q) non-invasively via the differential Fick (dFQ) method requires precise control of alveolar ventilation (VA) and is only suitable in ventilated patients. Bio-impedance methods on the other hand rely on assumptions of water lung content and spatial distribution of thoracic electrical impedance both often affected by cardiac surgery or poor cardiac performance. Probably for these reasons bio-impedance methods correlated poorly with the thermodilution method in previous studies. We evaluated a simple, automated method of a Fick based measurements of $\mathrm{Q}$, which requires no patient cooperation except for breathing through a facemask for a period of 5 minutes.

METHODS: Following REB approval we employed a sequential gas delivery circuit to measure $\mathrm{O}_{2}$ consumption $\left(\mathrm{VO}_{2}\right), \mathrm{CO}_{2}$ elimination $\left(\mathrm{VCO}_{2}\right)$ and to control $\mathrm{VA}$ independent of breathing pattern in a cohort of extubated, awake patients after on-pump coronary bypass surgery (CABG). This allowed calculation of dFQ during spontaneous ventilation. We used $\mathrm{VO}_{2}, \mathrm{dFQ}$ and arterial haemoglobin $\mathrm{O}_{2}$ saturation to calculate $\mathrm{SvO}$. We compared dFQ and SvO2 obtained by dFQ with thermodilution (TD) and directly sampled pulmonary artery (PA) blood respectively. $\mathrm{VO}_{2}$ and $\mathrm{VCO}_{2}$ was measured breath-by-breath. After drawing blood for $\mathrm{SvO} 2$ analysis, $3 \mathrm{dFQ}$ and 3 concurrent TD measurements were made. SvO2, Q and TD were recorded in a blinded fashion and compared for bias and precision using Bland-Altman analysis.

RESULTS: Thirty one tests were conducted in $25 \mathrm{ICU}$ patients on the first and second day after CABG surgery. Bias and SD for (TD-dFQ) was $-0.08 \mathrm{~L} / \mathrm{min} \pm 0.80 \mathrm{~L} / \mathrm{min}$. For $(\mathrm{PA}-\mathrm{SvO} 2)$ bias was $-15 \%$; however, SD was only $5.7 \%$.

CONCLUSION: This is the first report of bias and variability of $\mathrm{dFQ}$ and $\mathrm{SvO} 2$ compared to invasively measured values in spontaneously breathing patients. We demonstrated that noninvasive $\mathrm{dFQ}$ are accurate in CABG patients and may be used after cardiac surgery outside the CVICU setting or after the removal of indwelling catheters. Further investigation for noninvasive $\mathrm{SvO} 2$ measurements is warranted. 